\title{
The association between acromial anatomy and articular-sided partial thickness of rotator cuff tears
}

\author{
Cen Tao Liu ${ }^{1 \dagger}$, Jia Qing Miao ${ }^{1 \dagger}$, Hua Wang ${ }^{1}$, Heng an Ge ${ }^{2}$, Xian Hui Wang ${ }^{1 *}$ and Biao Cheng $^{2^{*}}$
}

\begin{abstract}
Background: Acromial anatomy has been found to be correlated with degenerative full-thickness rotator cuff tears in current studies. However, research on the relationship between acromial anatomy and articular-sided partial thickness of rotator cuff tears (PTRCTs) is still lacking. The purpose of this study was to evaluate whether these imaging graphic parameters exhibit any association between acromial anatomy and degenerative articular-sided PTRCTs.
\end{abstract}

Methods: Between January 2016 and December 2018, a total of 91 patients without a history of trauma underwent arthroscopy as an articular-sided PTRCT group. In the control group, with age- and sex-matched patients, we selected 91 consecutive outpatient patients who underwent shoulder magnetic resonance imaging (MRI) because of shoulder pain and an MRI diagnosis of only synovial hyperplasia and effusion. MRI was used to measure the acromial type, acromiohumeral distance (AHD), lateral acromial angle (LAA), acromion index (Al), and critical shoulder angle (CSA) by 2 independent observers.

Results: The acromion type, AHD and LAA showed no difference between degenerative articular-sided PTRCTs and controls ( $P=0.532,0.277$, and 0.108 , respectively). Al and CSA were significantly higher in degenerative articularsided PTRCTs ( $P=0.002$ and 0.003 , respectively). A good correlation was found between Al and CSA to measurement(Pearson correlation coefficient $=0.631$ ).

Conclusions: Our study revealed that higher Al and CSA were found in degenerative articular-sided PTRCTs. Acromial anatomy with a large acromial extension was associated with the occurrence of degenerative articularsided PTRCTs.

Keywords: Articular-sided partial thickness of rotator cuff tears, Acromial anatomy, Acromion index, Critical shoulder angle

\footnotetext{
* Correspondence: dr_xianhuiwang@outlook.com; dr_biaocheng@163.com

${ }^{+}$Cen Tao Liu and Jia Qing Miao contributed equally to this work and should be considered co-first authors.

'Department of Orthopedics, Putuo People's Hospital, Tongji University, No.

1291 Jiangning Road, Putuo District, 200060 Shanghai, China

2Department of Orthopedics, Shanghai Tenth People's Hospital, Tongji

University School of Medicine, No. 301 Yanchang Middle Road, Jing'an

District, 200072 Shanghai, China
}

(c) The Author(s). 2021 Open Access This article is licensed under a Creative Commons Attribution 4.0 International License, which permits use, sharing, adaptation, distribution and reproduction in any medium or format, as long as you give appropriate credit to the original author(s) and the source, provide a link to the Creative Commons licence, and indicate if changes were made. The images or other third party material in this article are included in the article's Creative Commons licence, unless indicated otherwise in a credit line to the material. If material is not included in the article's Creative Commons licence and your intended use is not permitted by statutory regulation or exceeds the permitted use, you will need to obtain permission directly from the copyright holder. To view a copy of this licence, visit http://creativecommons.org/licenses/by/4.0/. The Creative Commons Public Domain Dedication waiver (http://creativecommons.org/publicdomain/zero/1.0/) applies to the data made available in this article, unless otherwise stated in a credit line to the data. 


\section{Background}

Rotator cuff tears (RCTs) are a common shoulder disease and are highly prevalent among elderly people [1]. In addition to age, dominant arm and systemic diseases, a number of studies have reported that the risk factors for RCTs are related to the anatomic variations of acromions [2]. Regarding articular-sided partial thickness rotator cuff tears (PTRCTs) as the maximum proportion of PTRCTs [3], age-related degeneration has been reported in many articles [4]. Whether there is an association between acromial anatomy and degenerative articular-sided PTRCTs is still unclear.

Bigliani et al. [5] found three different types of acromions in 1991, and the one most commonly associated with RCT was the hook type. Other articles reported an acromion type without a relationship with RCTs [6]. Although rarely found in RCTs, Natsis et al. [7] reported convex acromions except for the three types noted above. In addition to the type of acromion, Banas et al. [8] reported a low lateral acromial angle (LAA) associated with RCT, which was later confirmed by other authors [9]. In full thickness rotator cuff tears (FTRCTs), Nyffeler et al. measured the index of the acromion and found that a large lateral extension of the acromion may exist [10]. Goutallier et al. [11] reported that the acromiohumeral distance (AHD) is smaller in RCTs, while others reported a decrease in AHD after FTRCTs [12]. Recently, some authors focused on the critical shoulder angle (CSA), as proposed by Moor et al. [13], and showed a strong correlation with RCTs and osteoarthritis.

The parameters described above were measured singly or were focused on the full thickness of the RCT. The results are still controversial. Humeral head translation secondary to FTRCT has been reported [12], while in shoulder model research, CSA and AI were positively correlated with humeral head inferior-superior translation [14], which may be biased in regarding whether it is the cause or the effect of FTRCTs. Studies have shown that osteophyte under acromion associated with bursal sided PTRC Ts [15], while tears on the articular side seem to be more common than those on the bursa side, the undersurface of the acromion usually was intact in articular-sided PTRCTs [16]. Therefore, this study mainly focused on the articular-sided PTRCTs. While Yoo et al. [4] found a higher CSA in articular-sided PTRCTs, other acromion parameters were not described. In this article, we evaluated the relationship of these common parameters (acromial type, acromiohumeral distance, lateral acromial angle, acromion index, and critical shoulder angle) with articular-sided PTRCTs.

\section{Methods}

\section{Patients}

We retrospectively evaluated data from consecutive patients at our institution from January 2016 until December 2018 who underwent arthroscopically confirmed isolated articular-sided PTRCTs. The patients we included had grade III articular-sided PTRCTs (exceeding $50 \%$ of the thickness of the tendon [17], was the failure predictors after conservative treatment of symptomatic PTRCT [18]); the diagnosis was based on their symptoms (pain or shoulder dysfunction), physical examination, and magnetic resonance imaging (MRI) and was finally confirmed by arthroscopy. These patients had supraspinatus or infraspinatus tear isolated or combined, and no subscapular was involved. All patients experienced failed conservative treatment for at least 3 months preoperatively, including activity modification, nonsteroidal anti-inflammatory drugs, physiotherapy, and steroid injections. A total of 91 patients (group 1) had shoulder joint sagittal and coronal oblique MRI before the surgery. The control group (group 2) contained 91 outpatient patients who underwent shoulder MRI and were age- and sex-matched. All of these patients underwent MRI because of shoulder pain, and were diagnosed (based on the MRI) with only synovial hyperplasia and effusion. The exclusion criteria were as follows: (1) articular-sided PTRCTs caused by trauma; (2) prior surgery on the same shoulder; (3) scapula or greater tuberosity fractures; (4) glenohumeral arthritis; (5) combined with other lesions (SLAP or long head biceps lesions); (6) shoulder infections; (7) other types of PTRCTs or FTRCTs; and (8) insufficient imaging evaluation.

\section{Measurements}

MRI is largely comparable to CT scan for evaluation of the glenoid in less extreme Walch glenoids [19] and accuracy in acromial morphology measurement [20]. MRI examinations were accomplished using a 1.5-T unit (Intera-Power, Philips Medical Systems, Best, the Netherlands). Each patient were placed in the supine position with their arms abducted to the sides. The elbows were extended and the palm upward. T1-weighted imaging, T2-weighted imaging and T2-weighted imaging with fat suppression in Sagittal, coronal oblique and axial planes were performed. The slice thickness was 5 $\mathrm{mm}$ with an interslice gap of $1 \mathrm{~mm}$. All MRIs were performed by the same facility. T1-weighted imaging were used to categorized the acromial type and made the measurement of LAA, AI, AHD and CSA.

The classification of acromial type was described by Bigliani et al. [5] and Natsis et al. [7]. We measured the undersurface of the acromion on sagittal oblique shoulder MRI and categorized the patients into four types: 
type I flat, type II curved, type III hooked and type IV convex.

The LAA was measured according to Banas et al. [8] on the coronal oblique shoulder MRI, and the angle was formed by a line parallel to the acromion undersurface and another line drawn along the superior and inferior most lateral glenoid (Fig. 1a).

AI measured the proportion of the distance from the glenoid plane to the most lateral point of the acromion and the distance from the glenoid plane to the most lateral point of the humeral head on coronal oblique shoulder MRI as described by Nyffeler et al. [10] (Fig. 1b).

The measurement of AHD according to Goupille et al. [21] on the coronal oblique shoulder MRI revealed the shortest distance between the inferior plane of the acromion and the superior plane of the humeral head (Fig. 1c).

We measured the CSA according to the method described by Moor et al. [13] on the coronal oblique shoulder MRI, with the angle formed by a line from the most lateral point of the inferior acromion to the inferior border of the glenoid and another line drawn along the superior and inferior most lateral glenoid (Fig. 1d).

Two independent well-trained orthopedic surgeons with experience with the shoulder performed the measurements while blinded to the patient's diagnosis.

\section{Statistical analyses}

All statistical analyses were performed using SPSS version 22 software. Interclass correlation coefficients (ICCs) were used to evaluate intraobserver and interobserver consistency in a two-way mixed model, and values greater than 0.75 were considered sufficient for reliability [22]. Associations were determined using the Pearson correlation coefficient (PCC). A PCC of less than 0.20 was determined to be poor; 0.21 to 0.40 , fair; 0.41 to 0.60 , moderate; 0.61 to 0.80 , good; and 0.81 to 1.00 , excellent [23]. The $\chi^{2}$ test was applied for categorical variables. The means for age, AHD, AI, LAA, and CSA from the two groups were compared using paired tests. A $p$ value less than 0.05 was considered significant. An area under the receiver operating characteristic (ROC) curve
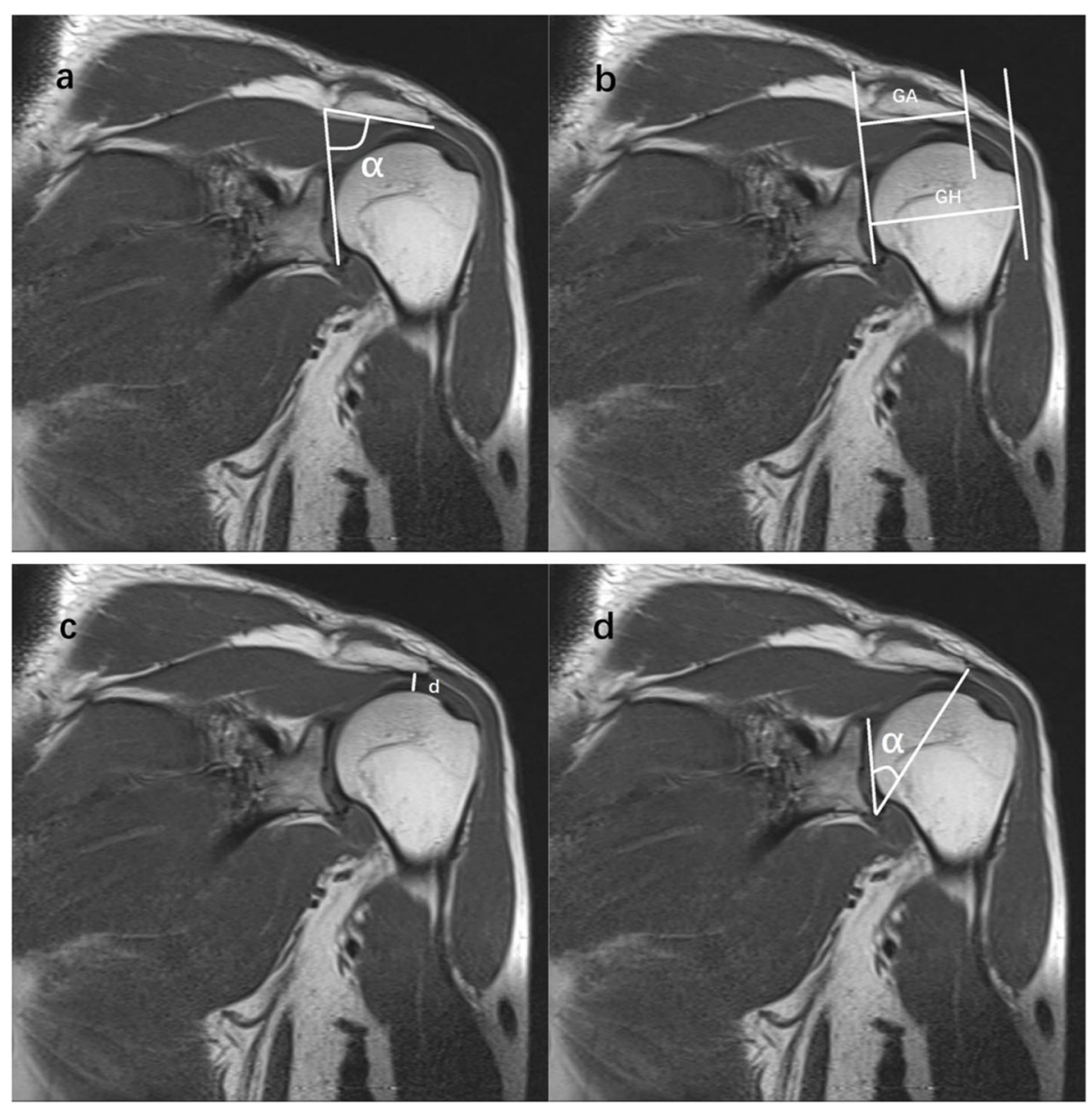

Fig. 1 Measurement parameters of acromial morphology. a lateral acromial angle (LAA, a), b acromion index (Al, $A l=G A / G H)$, $\mathbf{c}$ acromiohumeral distance (AHD, d), $\mathbf{d}$ critical shoulder angle (CSA, a) 
Table 1 Characteristics of articular-sided partial thickness of rotator cuff tears and control group

\begin{tabular}{llll}
\hline & Group 1 & Group 2 & $\boldsymbol{P}$ value \\
\hline $\mathrm{N}$ & 91 & 91 & \\
Age(years) & $60.75 \pm 10.3$ & $59.42 \pm 8.98$ & 0.354 \\
Gender & & & 0.285 \\
Male & 31 & 38 & \\
Female & 60 & 53 & 0.164 \\
Limb & & & \\
Left & 28 & 37 & \\
Right & 63 & 54 & 0.193 \\
BMI $\left(\mathrm{kg} / \mathrm{m}^{2}\right)$ & $24.68 \pm 4.29$ & $25.47 \pm 3.91$ & \\
\hline Age & & &
\end{tabular}

Age and $\mathrm{BMI}$ are means \pm standard division (SD)

$B M I$ body mass index

higher than 0.8 was considered significant. According to previous studies $[9,11,24-26]$, AI has the minimum effect size(0.537) compared with other parameters, the sample size was calculated to be at least 74 each group with a power of $90 \%$ and a $P$ value of 0.05 using $\mathrm{R}$ statistical environment (v4.4.1) .

\section{Results}

All demographic data of the patients are listed in Tables 1 and 2. In group 1 , there were 31 men and 60 women with an average age of $60.8 \pm 10.3$, with $69.2 \%$ right-handed. In group 2, there were 38 men and 53 women, with an average age of $59.4 \pm 8.98$ years and $59.3 \%$ were right handed. There was no significant difference between the two groups in these basic demographic data.

The ICCs of all imaging parameters were reliable, with intraobserver ICCs of 0.911 for AI, 0.979 for CSA, 0.972 for LAA and 0.934 for AHD, with interobserver ICCs of

Table 2 The relationship between variables and the articularsided partial thickness of rotator cuff tears

\begin{tabular}{lccc}
\hline & Group 1 & Group 2 & P value \\
\hline Acromion type(n,\%) & & & 0.532 \\
I & $25(27.5 \%)$ & $34(37.4 \%)$ & \\
II & $48(45.0 \%)$ & $42(46.2 \%)$ & \\
III & $12(13.2 \%)$ & $9(9.90 \%)$ & \\
IV & $6(6.60 \%)$ & $6(6.60 \%)$ & \\
$\mathrm{CSA}\left({ }^{\circ}\right)$ & $35.5 \pm 4.07$ & $33.7 \pm 3.96$ & 0.003 \\
$\mathrm{Al}$ & $0.683 \pm 0.09$ & $0.644 \pm 0.08$ & 0.002 \\
$\mathrm{LAA}\left({ }^{\circ}\right)$ & $78.3 \pm 4.97$ & $79.5 \pm 5.43$ & 0.108 \\
$\mathrm{AHD}(\mathrm{mm})$ & $9.35 \pm 1.29$ & $9.13 \pm 1.49$ & 0.277 \\
\hline $\mathrm{CSA}, \mathrm{Al}, \mathrm{LAA}$ and
\end{tabular}

CSA, Al, LAA and AHD are means \pm standard division (SD)

CSA critical shoulder angle, $A$ l acromion index, LAA lateral acromial angle, $A H D$ acromiohumeral distance
0.837 for AI, 0.960 for CSA, 0.946 for LAA and 0.875 for AHD.

The mean CSA values were significantly higher in articular-sided PTRCTs than in the controls (group 1: $35.5 \pm 4.07$ vs. group $2: 33.7 \pm 3.96, P=0.003$ ). The mean AI was also significantly higher in articular-sided PTRC Ts than in the controls (group 1: $0.683 \pm 0.0857$ vs. group 2: $0.644 \pm 0.0804, P=0.002$ ). For CSA in the diagnosis of articular-sided PTRCTs, the area under the ROC curve was 0.624 , and for AI in the diagnosis of articular-sided PTRCTs, the area under the ROC curve was 0.646 (Fig. 2).

Based on Bigliani [5] and Natsis's [7] classifications, the most common acromion type was type II in both groups. In group 1 , the acromions were $27.5 \%$ type I, $45.0 \%$ type II, $13.2 \%$ type III and $6.60 \%$ type IV. There were no differences within group 2 , with $37.4 \%$ type I, $46.2 \%$ type II, $9.90 \%$ type III and $6.60 \%$ type IV.

The mean LAA values were not significantly different between group 1 and group 2 (78.3 \pm 4.97 vs. $79.5 \pm 5.43$; $p=0.108$ ). The average AHD was also similar between the two groups (group 1: $9.35 \pm 1.29$ vs. group 2: $9.13 \pm$ $1.49, P=0.277$ ).

We found a good correlation between CSA and AI and a fair correlation between LAA and CSA and AI, AHD and CSA, and AHD and AI. Poor correlations were found between AHD and LAA and between age and acromion and the other parameters (Table 3).

\section{Discussion}

The main finding of the study was that statistically significant differences in AI and CSA were found between the articular-sided PTRCT group and the matched control group utilized MRI. Some studies have suggested that FTRCTs originate from partial tears [27]. Although the articular-sided PTRCTs is not in direct contact with the acromion, however, this study suggests a correlation between each other. It shows that the relationship between acromion and rotator cuff is more than direct attrition.

AI was first described by Nyffeler et al. [10] in 2006, who reported a larger AI in FTRCTs than in controls. In contrast to traumatic RCTs, Balke et al. [28] also showed a higher tendency in degenerative RCTs. While Pandey et al. [29] revealed an association between a higher AI and FTRCTs, they also showed no significant association in bursal-sided PTRCTs. Jung Ryul et al. [25] took articular-sided PTRCTs into consideration as a control group for FTRCTs and showed a significantly lower AI in articular-sided PTRCTs, the control group with intact rotator cuff tendons was not included. In our articularside PTRCTs, with a mean value 0.04 higher than the control, the degree seems lower than the FTRCT with Nyffeler (0.09) and Pandey (0.06). This indicates that a 


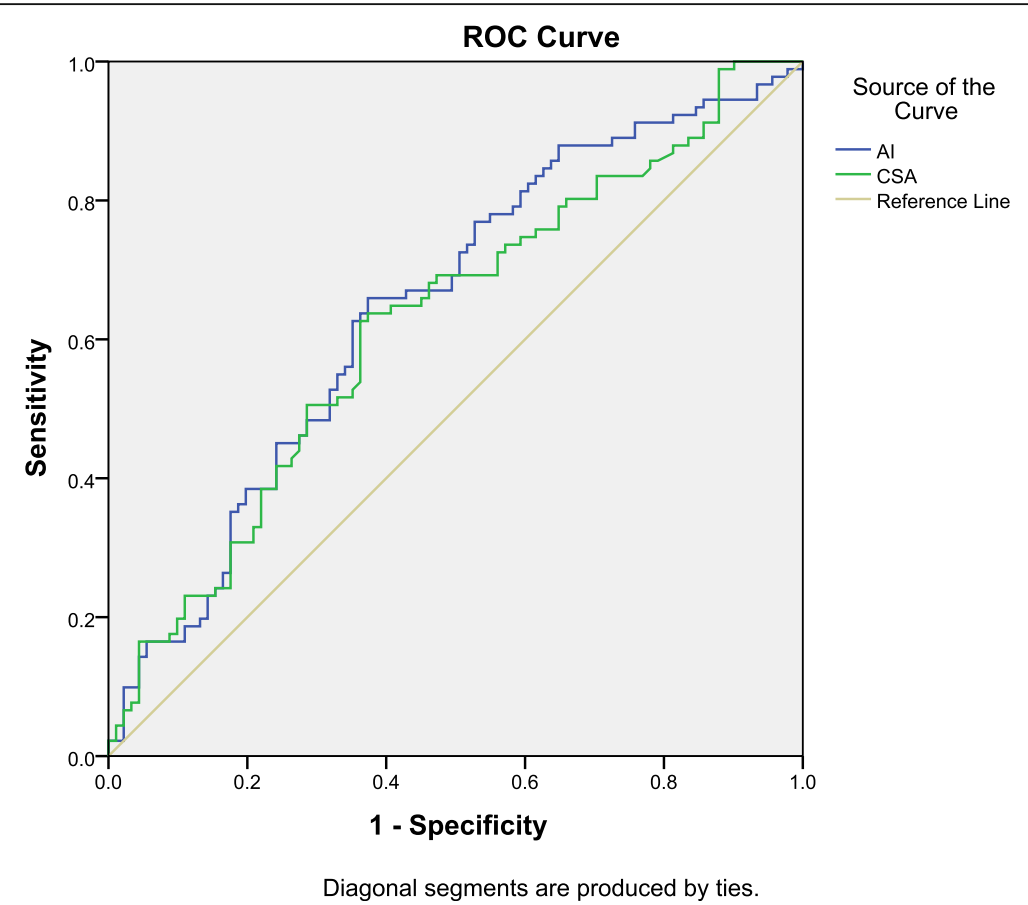

Fig. 2 Receiver operating characteristic curves for the acromion index in blue and the critical shoulder angle in green. The reference line is indicated in yellow

Table 3 The correlations between variables

\begin{tabular}{|c|c|c|c|c|c|c|}
\hline & Al & AHD & LAA & CSA & Age & Acromion type \\
\hline \multicolumn{7}{|l|}{$\mathrm{Al}$} \\
\hline Pearson Correlation & 1 & -0.207 & -0.378 & 0.631 & 0.014 & -0.075 \\
\hline Sig. (2-tailed) & & 0.005 & 0.000 & 0.000 & 0.854 & 0.317 \\
\hline \multicolumn{7}{|l|}{$\mathrm{AHD}$} \\
\hline Pearson Correlation & -0.207 & 1 & 0.005 & -0.232 & 0.098 & 0.083 \\
\hline Sig. (2-tailed) & 0.005 & & 0.943 & 0.002 & 0.189 & 0.264 \\
\hline \multicolumn{7}{|l|}{ LAA } \\
\hline Pearson Correlation & -0.378 & 0.005 & 1 & -0.357 & -0.077 & -0.007 \\
\hline Sig. (2-tailed) & 0.000 & 0.943 & & 0.000 & 0.299 & 0.929 \\
\hline \multicolumn{7}{|l|}{ CSA } \\
\hline Pearson Correlation & 0.631 & -0.232 & -0.357 & 1 & 0.123 & -0.100 \\
\hline Sig. (2-tailed) & 0.000 & 0.002 & 0.000 & & 0.099 & 0.181 \\
\hline \multicolumn{7}{|l|}{ Age } \\
\hline Pearson Correlation & 0.014 & 0.098 & -0.077 & 0.123 & 1 & 0.081 \\
\hline Sig. (2-tailed) & 0.854 & 0.189 & 0.299 & 0.099 & & 0.274 \\
\hline \multicolumn{7}{|l|}{ Acromion type } \\
\hline Pearson Correlation & -0.075 & 0.083 & -0.007 & -0.100 & 0.081 & 1 \\
\hline Sig. (2-tailed) & 0.317 & 0.264 & 0.929 & 0.181 & 0.274 & \\
\hline
\end{tabular}

Al acromion index, $A H D$ acromiohumeral distance, $L A A$ lateral acromial angle, CSA critical shoulder angle 
higher degree difference in AI may cause a higher degree of RCT [25]. According to Thomas et al. [30], without distinguishing bursal-sided and articular-sided PTRCTs, they show a nonsignificant value between PTRCTs and FTRCTs. Therefore, a higher value of AI may exist in articular-sided PTRCTs and this was confirmed in our study. Although we can easily meet bursal-sided tear patients because bursal-sided tear had a higher degree of pain than articular-sided tear [31], but it is easier to make a tear on the articular side than on the bursal side [3]. Previous literature have shown that the articular side rotator cuff has poor vascularity [32], and biomechanical studies demonstrated the articular side elongated poorly, cause the ultimate stress is lower on the articular side [33], especially when there is a greater strain caused by the deltoid middle branch with a larger AI [10].

In recent years, CSA was first described by Moor et al. [13] as having a good association in FTRCTs with a higher value. As confirmed by later authors [24, 34], although Bjarnison et al. [35] reported no correlation between CSA and RCTs, there was a lack of distinguish PTRCTs and FTRCTs. Seo J et al. [36] found a higher CSA in articular-sided PTRCTs and no correlation with bursal-sided PTRCTs, and this result was consistent with another study described by Shinagawa et al. [34] with an overall lower CSA value in Asian people. By established shoulder model, Villatte et al [37] and Gerber et al [38] found that RCT overload particularly at low degrees of active abduction with a high CSA value. Because a higher CSA value may produce larger shear force, RCT need compensate additional shear force to maintain shoulder stability. This lead to increased muscle use may result in degenerative rotator cuff tears. The mean CSA value was different from that in our study, but we showed a similar tendency of higher CSA values in articular-sided PTRCTs.

Although a hook type seemed to have a higher association with RCTs according to Bigliani et al. [5], recently, an excessive hook type acromion with a slope larger than $43^{\circ}$ was proven to be related to FTRCTs [23], but the overall acromion type showed no significance in RCT patients. By using shoulder magnetic resonance arthrography, Kim et al. [6] found that the acromion type was not associated with RCTs, bursal-sided PTRC Ts or articular-sided PTRCTs. The association between rotator cuff tear and acromion type may be due to the wear of acromion to the rotator cuff on the bursal side. The acromion type had no correlation with articularsided PTRCTs with an intact bursal side in this article, consistent with the previous studies. The mean value of LAA in our study was slightly lower in the patient group, but there was no statistical significance. In a previous study, Balke et al. [23] and Banas et al. [8] reported a significantly lower LAA value in degenerative RCTs.
While the RCT group in Balke et al. did not differentiate the analysis by PTRCTs, bias caused by bursal-sided PTRCTs may exist. Saupe et al. [12] found that a shorter AHD was associated with FTRCT, and the progression of fatty degeneration increased migration. Goutallier et al. [11] proposed that an AHD less than $6 \mathrm{~mm}$ would be significantly associated with FTRCTs. In our study, an AHD similar to the control group and no AHD below $6 \mathrm{~mm}$ indicated that the humeral head did not migrate due to articular-sided PTRCTs. Previous study thought a smaller LAA may reduce the available volume and then impose pressure on the rotator cuff increase the tear risk. This is different from this study, while acromioplasty could increase the subacromial volume and AHD, if the main cause of articular-sided PTRCTs is not the acromion type, a smaller LAA and AHD, acromioplasty in surgical management would not be the optimum choice of treatment. Budoff et al. [39] reported PTRCTs needn't acromioplasty, Weber [40] reported a higher rerupture rate and poor outcome despite adequate acromioplasty in articular-sided PTRCTs. This may indicated acromion type, a smaller LAA and AHD not the main cause of articular-sided PTRCTs.

A good correlation between CSA and AI was found in this article, which is similar to a previous study [41]. According to Moor et al. [13], CSA considered both glenoid and acromion anatomy as good parameters to predict RCT and osteoarthritis. Rhee et al. [42] showed good correlations between CSA and RCT and measurement of CSA did not calculate the morphology of the humeral head. At the same time, there are also literature reports that lateral acromial roof extension had a greater association with RCT than glenoid inclination [43]. AI is the ratio between lateral acromion with lateral humeral head to lateral glenoid [10]. In our study, glenohumeral arthritis was ruled out in all patients, so a good correlation appeared when the humeral head was normal. Although there was a higher CSA and AI in articular-sided PTRCTs, the area under the ROC curve showed a low diagnostic value; thus, the use of these parameters to diagnose articular-sided PTRCTs should proceed with caution.

Some limitations of this study should be considered. First, potential measurement bias may exist, although two well-trained orthopedists independently made the measurement without a previously known diagnosis. Second, this is a retrospective study in which all patients were symptomatic and underwent surgery, and selection bias may exist owing to asymptomatic articular-sided PTRCTs. Finally, since plain radiographs or computed tomography were not used, the accuracy of MRI measurement was not further verified, which also might have caused a bias. 


\section{Conclusions}

Our study revealed that higher AI and CSA were found in degenerative articular-sided PTRCTs. Acromial anatomy with a large acromial extension was associated with the occurrence of degenerative articular-sided PTRCTs.

\section{Abbreviations}

RCT: Rotator cuff tear; PTRCTs: Partial thickness of rotator cuff tears; FTRC T: Full thickness of rotator cuff tears; MRI: Magnetic resonance images; AHD: Acromiohumeral distance; LAA: Lateral acromial angle; Al: Acromion index; CSA: Critical shoulder angle; ICC: Interclass correlation coefficients; PCC: Pearson correlation coefficient; ROC: Receiver operating characteristic: SLAP: Superior labrum from anterior to posterior; BMI: Body mass index

\section{Acknowledgements}

None.

\section{Authors' contributions}

CTL and BC conceived of the study and participated in its design. CTL and HAG measured the parameters. XHW performed the statistical analysis. HW and JQM drafted the manuscript. All authors read and approved the final manuscript.

\section{Funding}

The study was supported by the grants from the Natural Science Foundation of China (No. 81972095), Scientific Research Projects supported by the Shanghai Committee of Science and Technology (No. 19441901702), and horizontal research funds from Shanghai Ruiji Trading Company and Shanghai Bojin Kinetic Medical Technology Co. Ltd (No. shrj20170501sy and No. 201705-QP-C1085-011), and Project for Capacity Promotion of Putuo District Clinical Special Disease(No. 2020tszb04)

\section{Availability of data and materials}

The datasets used and/or analysed during the current study are available from the corresponding author on reasonable request.

\section{Declarations}

\section{Ethics approval and consent to participate}

This study was approved by the Ethics Committee of Shanghai Tenth People's hospital in accordance with the Declaration of Helsinki. Verbal informed consents were obtained from all patients, which was approved by the Ethics Committee of Shanghai Tenth People's hospital.

\section{Consent for publication}

Not applicable.

\section{Competing interests}

The authors declare that they have no competing interests.

Received: 16 March 2021 Accepted: 23 August 2021

Published online: 06 September 2021

\section{References}

1. Yamamoto A, Takagishi K, Osawa T, Yanagawa T, Nakajima D, Shitara H, Kobayashi T. Prevalence and risk factors of a rotator cuff tear in the general population. J Shoulder Elbow Surg. 2010;19(1):116-20.

2. McGinley JC, Agrawal S, Biswal S. Rotator cuff tears: association with acromion angulation on MRI. Clin Imaging. 2012;36(6):791-6.

3. Payne LZ, Altchek DW, Craig EV, Warren RF. Arthroscopic treatment of partial rotator cuff tears in young athletes. A preliminary report. Am J Sports Med. 1997:25(3):299-305

4. Yoo JS, Heo K, Yang JH, Seo JB. Greater tuberosity angle and Critical shoulder angle according to the Delamination Patterns of rotator cuff tear. J Orthop. 2019;16(5):354-8.

5. Bigliani LU, Ticker JB, Flatow EL, Soslowsky LJ, Mow VC. The relationship of acromial architecture to rotator cuff disease. Clin Sports Med. 1991;10(4): 823-38.
6. Kim JM, Kim YW, Kim HS. The relationship between rotator cuff tear and four acromion types: cross-sectional study based on shoulder magnetic resonance imaging in 227 patients. Acta Radiol. 2019;60(5):608-14.

7. Natsis K, Tsikaras P, Totlis T, Gigis I, Skandalakis P, Appell HJ, Koebke J. Correlation between the four types of acromion and the existence of enthesophytes: a study on 423 dried scapulas and review of the literature. Clin Anat. 2007;20(3):267-72

8. Banas MP, Miller RJ, Totterman S. Relationship between the lateral acromion angle and rotator cuff disease. J Shoulder Elbow Surg. 1995;4(6):454-61.

9. Moor BK, Wieser K, Slankamenac K, Gerber C, Bouaicha S. Relationship of individual scapular anatomy and degenerative rotator cuff tears. J Shoulder Elbow Surg. 2014;23(4):536-41.

10. Nyffeler RW, Werner CM, Sukthankar A, Schmid MR, Gerber C. Association of a large lateral extension of the acromion with rotator cuff tears. J Bone Joint Surg Am. 2006:88(4):800-5.

11. Goutallier D, Le Guilloux P, Postel JM, Radier C, Bernageau J, Zilber S. Acromio humeral distance less than six millimeter: its meaning in fullthickness rotator cuff tear. Orthop Traumatol Surg Res. 2011;97(3):246-51.

12. Saupe N, Pfirrmann CW, Schmid MR, Jost B, Werner CM, Zanetti M. Association between rotator cuff abnormalities and reduced acromiohumeral distance. AJR Am J Roentgenol. 2006;187(2):376-82.

13. Moor BK, Bouaicha S, Rothenfluh DA, Sukthankar A, Gerber C. Is there an association between the individual anatomy of the scapula and the development of rotator cuff tears or osteoarthritis of the glenohumeral joint?: A radiological study of the critical shoulder angle. Bone Joint J. 2013; 95-B(7):935-41.

14. Engelhardt C, Farron A, Becce F, Place N, Pioletti DP, Terrier A. Effects of glenoid inclination and acromion index on humeral head translation and glenoid articular cartilage strain. J Shoulder Elbow Surg. 2017;26(1):157-64

15. Ogawa K, Yoshida A, Inokuchi W, Naniwa T. Acromial spur: relationship to aging and morphologic changes in the rotator cuff. J Shoulder Elbow Surg. 2005:14(6):591-8.

16. Ozaki J, Fujimoto S, Nakagawa Y, Masuhara K, Tamai S. Tears of the rotator cuff of the shoulder associated with pathological changes in the acromion. A study in cadavera. J Bone Joint Surg Am. 1988;70(8):1224-30.

17. Ellman H. Diagnosis and treatment of incomplete rotator cuff tears. Clin Orthop Relat Res. 1990;(254):64-74.

18. Nakhaei Amroodi M, Salariyeh M. Predictors of failure after conservative treatment of symptomatic partial-thickness rotator cuff tear. J Shoulder Elbow Surg. 2020:29(1):113-20.

19. Lowe JT, Testa EJ, Li X, Miller S, DeAngelis JP, Jawa A. Magnetic resonance imaging is comparable to computed tomography for determination of glenoid version but does not accurately distinguish between Walch B2 and C classifications. J Shoulder Elbow Surg. 2017;26(4):669-73.

20. Chalmers PN, Beck L, Miller M, Kawakami J, Dukas AG, Burks RT, Greis PE, Tashijan RZ. Acromial morphology is not associated with rotator cuff tearing or repair healing. J Shoulder Elbow Surg. 2020;29(11):2229-39.

21. Goupille $P$, Anger $C$, Cotty $P$, Fouquet $B$, Soutif $D$, Valat JP. Value of standard radiographies in the diagnosis of rotator cuff rupture. Rev Rhum. 1993;60(6):440-4.

22. Cicchetti Domenic V. Guidelines, criteria, and rules of thumb for evaluating normed and standardized assessment instruments in psychology. Psychol Assess. 1994;6(4):284-90.

23. Balke M, Schmidt C, Dedy N, Banerjee M, Bouillon B, Liem D. Correlation of acromial morphology with impingement syndrome and rotator cuff tears. Acta Orthop. 2013:84(2):178-83.

24. Epstein RE, Schweitzer ME, Frieman BG, Fenlin JM Jr., Mitchell DG. Hooked acromion: prevalence on MR images of painful shoulders. Radiology. 1993; 187(2):479-81.

25. Jung Ryul K, Keun Jung R, In Tae H, Byung Kook K, Jae Hwa K. Can a high acromion index predict rotator cuff tears? Int Orthop. 2012;36(5):1019-24.

26. Spiegl UJ, Horan MP, Smith SW, Ho CP, Millett PJ. The critical shoulder angle is associated with rotator cuff tears and shoulder osteoarthritis and is better assessed with radiographs over MRI. Knee Surg Sports Traumatol Arthrosc. 2016:24(7):2244-51.

27. Jeong JY, Min SK, Park KM, Park YB, Han KJ, Yoo JC. Location of rotator cuff tear initiation: a magnetic resonance imaging study of 191 shoulders. Am J Sports Med. 2018;46(3):649-55

28. Balke M, Liem D, Greshake O, Hoeher J, Bouillon B, Banerjee M. Differences in acromial morphology of shoulders in patients with degenerative and traumatic supraspinatus tendon tears. Knee Surg Sports Traumatol Arthrosc. 2016:24(7):2200-5 
29. Pandey V, Vijayan D, Tapashetti S, Agarwal L, Kamath A, Acharya K, Maddukuri S, Willems WJ. Does scapular morphology affect the integrity of the rotator cuff? J Should Elbow Surg. 2016;25(3):413-21.

30. Thomas K, Balkan C, Sabine L, Heiko R, Mohammed E. Intraarticular lesions in calcifying tendinitis: incidence and association with the acromion index. Arch Orthop Trauma Surg. 2011;131(3):325-9.

31. Fukuda H. Partial-thickness rotator cuff tears: a modern view on Codman's classic. J Shoulder Elbow Surg. 2000;9(2):163-8.

32. Rudzki JR, Adler RS, Warren RF, Kadrmas WR, Verma N, Pearle AD, Lyman S, Fealy S. Contrast-enhanced ultrasound characterization of the vascularity of the rotator cuff tendon: age- and activity-related changes in the intact asymptomatic rotator cuff. J Shoulder Elbow Surg. 2008;17(1 Suppl):96s100 s.

33. Nakajima T, Rokuuma N, Hamada, . K, Tomatsu T, Fukuda. Histologic and biomechanical characteristics of the supraspinatus tendon: Reference to rotator cuff tearing. J Shoulder Elbow Surg. 1994;3(2):79-87.

34. Shinagawa K, Hatta T, Yamamoto N, Kawakami J, Shiota Y, Mineta M, Itoi E. Critical shoulder angle in an East Asian population: correlation to the incidence of rotator cuff tear and glenohumeral osteoarthritis. J Shoulder Elbow Surg. 2018;27(9):1602-6.

35. Bjarnison AO, Sørensen TJ, Kallemose T, Barfod KW. The critical shoulder angle is associated with osteoarthritis in the shoulder but not rotator cuff tears: a retrospective case-control study. J Shoulder Elbow Surg. 2017;33(10): e53-4.

36. Seo J, Heo K, Kwon S, Yoo J. Critical shoulder angle and greater tuberosity angle according to the partial thickness rotator cuff tear patterns. Orthopaed Traumatol Surg Res. 2019;105(8):1543-8.

37. Villatte $G$, van der Kruk E, Bhuta Al, Zumstein MA, Moor BK, Emery RJH, Bull AMJ, Reilly P. A biomechanical confirmation of the relationship between critical shoulder angle (CSA) and articular joint loading. I Shoulder Elbow Surg. 2020;29(10):1967-73.

38. Gerber C, Snedeker JG, Baumgartner D, Viehöfer AF. Supraspinatus tendon load during abduction is dependent on the size of the critical shoulder angle: a biomechanical analysis. J Orthop Res. 2014;32(7):952-7.

39. Budoff JE, Nirschl RP, Guidi EJ. Débridement of partial-thickness tears of the rotator cuff without acromioplasty. Long-term follow-up and review of the literature. J Bone Joint Surg Am. 1998;80(5):733-48.

40. Weber SC. Arthroscopic debridement and acromioplasty versus mini-open repair in the management of significant partial-thickness tears of the rotator cuff. Orthop Clin North Am. 1997;28(1):79-82.

41. Heuberer PR, Plachel F, Willinger L, Moroder P, Laky B, Pauzenberger L, Lomoschitz F, Anderl W. Critical shoulder angle combined with age predict five shoulder pathologies: a retrospective analysis of 1000 cases. BMC Musculoskelet Disord. 2017;18(1):259.

42. Rhee SM, Kim JY, Kim JY, Cho SJ, Kim JH, Rhee YG. The critical shoulder angle: can it be sufficient to reflect the shoulder joint without the humeral head? J Shoulder Elbow Surg. 2019;28(4):731-41.

43. Beeler S, Hasler A, Götschi T, Meyer DC, Gerber C. Critical shoulder angle: acromial coverage is more relevant than glenoid inclination. J Orthop Res. 2019:37(1):205-10.

\section{Publisher's Note}

Springer Nature remains neutral with regard to jurisdictional claims in published maps and institutional affiliations.

Ready to submit your research? Choose BMC and benefit from:
- fast, convenient online submission
- thorough peer review by experienced researchers in your field
- rapid publication on acceptance
- support for research data, including large and complex data types
- gold Open Access which fosters wider collaboration and increased citations
- maximum visibility for your research: over 100M website views per year
At BMC, research is always in progress.
Learn more biomedcentral.com/submissions

